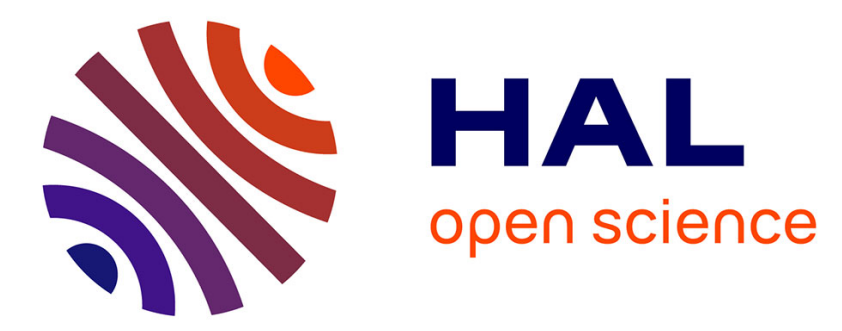

\title{
Artificial Intelligence and Reliability of Accounting Information
}

\author{
Saeed Askary, Nasser Abu-Ghazaleh, Yasean A. Tahat
}

\section{To cite this version:}

Saeed Askary, Nasser Abu-Ghazaleh, Yasean A. Tahat. Artificial Intelligence and Reliability of Accounting Information. 17th Conference on e-Business, e-Services and e-Society (I3E), Oct 2018, Kuwait City, Kuwait. pp.315-324, 10.1007/978-3-030-02131-3_28. hal-02274162

\section{HAL Id: hal-02274162 \\ https://hal.inria.fr/hal-02274162}

Submitted on 29 Aug 2019

HAL is a multi-disciplinary open access archive for the deposit and dissemination of scientific research documents, whether they are published or not. The documents may come from teaching and research institutions in France or abroad, or from public or private research centers.
L'archive ouverte pluridisciplinaire HAL, est destinée au dépôt et à la diffusion de documents scientifiques de niveau recherche, publiés ou non, émanant des établissements d'enseignement et de recherche français ou étrangers, des laboratoires publics ou privés. 


\title{
Artificial Intelligence and Reliability of Accounting Information
}

\author{
Saeed Askary, Nasser Abu-Ghazaleh, Yasean A. Tahat \\ Gulf University for Science and Technology, Hawally, Kuwait \\ \{askary.s, AbuGhazaleh.N, Tahat.Y@gust.edu.kw\}
}

\begin{abstract}
Producing relevant and reliable accounting information is the main responsibility of accounting profession. Reliability and relevance of accounting information heavily depend on a sound internal control system as well as management and employees ethical and integrity characteristics. This paper shows how Artificial Intelligence innovatively works with the internal controls systems to help managers to produce high-quality accounting information by reducing information risk. Despite many types of research proposed using Artificial Intelligence in accounting and auditing, but none of them directly showed how to reduce information risk using Artificial Intelligence. The research benefits companies cut many costs and losses of failing to produce reliable accounting information, help managers to make a better decision and in overall improve entities performances. This paper proposes a general model to be applied by all type of business entities how practically use Artificial Intelligence to automate removing the weakness of internal control systems. This, in turn, reduces control risk, detection risk and increase audit quality by reducing accounting information risk.
\end{abstract}

Keywords: Artificial Intelligence, Accounting information, Internal control systems, Reliability, Relevance.

\section{Introduction}

The Institute of Chartered Accountants of England and Wales (ICAEW) issued "Artificial intelligence and the future of accountancy" article in 2017 and addressed applying and using this technique in accounting and auditing profession. ICAEW viewed from many successes in three perspectives: long-term visions, understand technology and application for accounting. Designing and developing knowledgeable organization using artificial intelligence technique is growing rapidly ([26]; [21]). All companies in the global business and economy deal with technology issues to survive in which Artificial Intelligence would be an appropriate solution for this problem ([16]). Global Survey in Artificial Intelligence (2017) Forrester Research has predicted a "greater than 300\% increase in investment in artificial intelligence in 2017”, compared with 2016, a testament to the sector's rapid global growth. ([25]) banking and manufacturing would be more benefited from Artificial Intelligence. Artificial Intelligence application in accounting includes big data analysis, produce accurate, reliable, and on-time accounting information for the users. Brown et al. (1995) considered that Artificial Intelligence impact significantly on accounting and auditing practices as well as internal control structure[5].

In long-term vision Artificial Intelligence helps accounting profession by focus on purpose of accounting profession for organization which is to use accounting information to make good decision by users of the information. In exploiting powerful technologies, think radically and being adaptable. In understanding technology, Artificial Intelligence helps human decision-making, strengths of machine learning, and to utilize the decision process of enterprises information management. 
Accounting systems are moving very fast toward being more integrated with and intelligent logic through applying Artificial Intelligence ([6]). Since the purpose of accounting profession is to provide relevant and reliable financial information for various users to make useful decisions, using Artificial Intelligence to produce such a reliable and relevant information would be more supportive. However, accounting systems are significantly depending on the internal control system to produce such a reliable information. For this reason, investigating how Artificial Intelligence help managers to remove weaknesses of internal control system to produce useful accounting information for the users would be questionable. This paper will show how Artificial Intelligence will enhance the efficiency and effectiveness of internal control system in producing highly reliable accounting information.

Artificial Intelligence is a mix of software and equipment as a substitute for human intelligence enable to solve complex business problems using reasoning, learning, elucidating, and recognizing patterns same as human expert. Artificial Intelligence uses expert system instead of expert human and apply machine intelligence instead of human intelligence. Artificial Intelligence has great impact on helping manager in making decision by reducing repetitive decisions, providing more precise information, simplifying complex decision factors, and fact processing data analysis [24].

The benefits of Artificial Intelligence in the future of accounting including reducing automotive tasks, increasing produced reliable financial information, simplifying complicated accounting and auditing cases, more accurate and precise information and timeliness for decision makers [5]. The gap in the literature shows that how Artificial Intelligence can reduce accounting information risk to increase confidence of the information users. This paper aims to address the gap of role of Artificial Intelligence in reducing accounting information risk.

The purpose of the study is to see how Artificial Intelligence help companies to remove internal control weaknesses to produce reliable accounting information. Although, there are many research about the importance of the Artificial Intelligence in business decision making but there is not any research show how Artificial Intelligence can improve the quality of accounting information by strengthens of the internal control systems. The rest of the paper is organized in this way. Frist, we review literature about the use of Artificial Intelligence in accounting and auditing profession. Then, we show how Artificial Intelligence can be applied in developing and designing internal control system to produce reliable accounting information. Finally, the paper shows how Artificial Intelligence can reduce the accounting information risk.

\section{The importance of Reliability of Accounting Information}

According to Maines and Wahlen (2006) reliability is an essential characteristic for accounting information which is useful for decision making and it represents the extent to which the information is unbiased, free from error, and representationally faithful [22]. To achieve this, one of the crucial factor is to establish a strong internal control system. SEC defines internal control as 'a process, effected by an entity's board of directors, management and other personnel, designed to provide reasonable assurance regarding the reliability of financial reporting'. As stated by Elbannan (2009) the higher the quality of internal controls over financial reporting, and thus user better trust on the reports for making better decision [12].

One of the main problem in producing low quality accounting information is related to the weakness of internal control systems. The Sarbanes-Oxley Act of 2002 highlights the importance of information system controls by requiring management and auditors to report on the effectiveness of internal controls over the financial reporting component of the firm's management information systems [12]. One of the 
main reason for weakness of the internal control systems is related to poor corporate governance. Also, cost-benefit constrain may impact the developing, designing, implementing, and maintain an effective internal control systems[14].

To deal with removing weakness of the internal control system have been researched by many studies (e.g. see [6]; [9]; [12]). After initiating SOX 2002, the management of the companies, auditors, audit committee and SEC as well as PCAOB have paid more attention to the issue of removing weakness the internal control system [20]. Also, modern technology helped business enterprise to reduce the weakness of the internal control system. However, using effective innovate means such as Artificial Intelligence is more predictable then before.

There are a handful of research in accounting and auditing showing how Artificial Intelligence application to help to uncovered relationship between those variables affecting accounting information [18]; [28]. Artificial Intelligence help better to cover all variables involved with a problem and not just cover a few of them in solving accounting and auditing dilemma. Artificial Intelligence would be one of the solution to remove weakness of internal control systems. Generally, Artificial Intelligence use the multitude of related technologies and then integrating those technologies into full solutions. Kahraman, et al. (2011) showed how intelligence techniques have been used in information management systems [16]. Artificial Intelligence use Intelligent decision support systems (IDSS) to automate performing and running activities. IDSS term describes decision support systems that heavily rely on using artificial intelligence techniques. The intelligence techniques used in enterprise information management (EIM) such as fuzzy set theory (FST), multi-agent systems (MAS), neural networks (NNs), genetic algorithms (GAs), ant colony optimization(ACO) and particle swarm optimization (PSO) (Ibid). For example, fuzzy logic and theory and neural network used for auditing research to predict fraud and improving audit quality (AlAli et al. 2018, Beynon et al. 2004).

\section{The Role of Internal Control Systems}

The main purpose of almost every internal control system is to manage risks factor that prevent an enterprise to achieve their strategic goals. Every organization aims to achiever their strategic goals by designing, developing, implementing and maintaining an effective and efficient internal control systems. According to SOX (2002), management of publicly listed company is responsible to develop and maintain an effective and efficient internal control system. Figure 1 is an adjusted model of Ling's study that shows a dynamic internal control system.

Figure 1. Modified Ling (2015) Model 


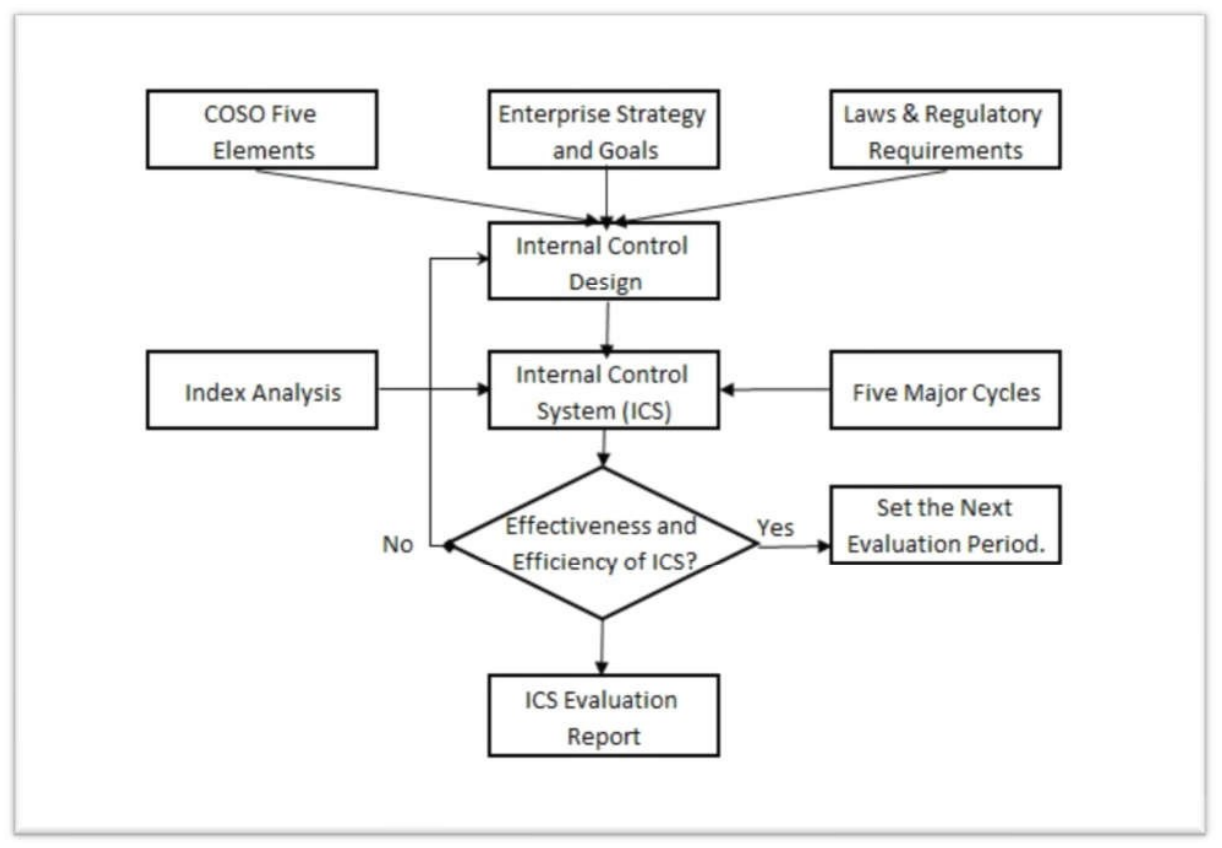

According to Ling (2015) and as the figure 1 shows, internal control systems can be in optimal position by continuous internal control assessment and improvement. This could be achieved by applying COSO framework. According to Länsiluoto et al. (2016) the COSO of the Treadway Commission has issued two globally recognized internal control frameworks. The first is Internal Control - Integrated Framework, and was published in 1992 and the second called COSO Enterprise Risk Management, issued in 2004. The frameworks of both are based on a conceptual framework compatible with COSO ERM (2004). COSO identifies that a central role of internal control is"...a means to identify and analyze risks, and to develop and manage appropriate responses to risks within acceptable levels and with a greater focus on anti-fraud measures...." Internal control has three types of objectives; operations, reporting, and compliance objectives [17].

CEO and CFO of public company's top management, has a responsibility to report through the management report on the effectiveness of internal control over financial reporting [13]. In internal control theory, the more stronger is the internal control system, the more reliable and high quality would be the accounting information and financial reporting. That is why external auditors should examine and report on the internal control effectiveness and efficiency along with audit report about the financial statements. Also, internal auditors, working under the audit committee, continuously monitor the issue and report to the committee on on-going basis.

The main weakness of internal control systems in every organization is related to the system disability to protect the assets and producing reliable and relevant accounting information. The system, at risk, allows fraudulent financial transaction being processed to the system in which produce unreliable accounting information. In this case, control risk would be high and auditor should be notified of detection risk. Thus, all those material misstatements that internal controls could not detect them, the auditor should find them by control test and in the worse case by increasing audit evidence in which will increase audit costs. 


\section{Internal Controls Systems and Information Reliability}

In July, 2002, the United States government approved the Law Sarbanes-Oxley Act (SOX) in response to a wide range of financial scandals (e.g. Enron, WorldCom, etc.); one of the concern was about the internal control system strengthens and improving the accounting information quality. The general theory drawn from the law was based on the interaction between good corporate governance mechanism, strong internal control system, and high level of auditor's independence to produce reliable accounting information.

Canelas et. al. (2013) raised the question about how information technologies through Artificial Intelligence can help and support decision making related to the SOX mandates [7]. There are two type of studies; one before the SOX Law and another one after the law introduced. The studies showed how companies concern about publishing truthful financial reports and suggesting some intelligent systems to support external auditors in their decision making processes to state if those reports were truthful or not. AI should help managers to produce the information in which would be more trustable for the users. This could be by removing and resolving complicated situations through Artificial Intelligence such as weakness of internal control system of cash, inventory, etc.

Doyle et al. (2005) studied the relationship between weak internal control and increased opportunities for intentional earnings management techniques and unintentional accounting estimation errors [11]. If Artificial Intelligence can strength the internal control systems, then the opportunities for intentional mistakes would be decreased. In turn, this will decrease control risk and higher the quality accounting information for the users.

Artificial Intelligence, in current high-powered technology, should help managers to remove weakness of internal controls through recognizing, analyzing and removing those weakness and then provide final solutions with more accurate and quick remedies before many damages incurred to the entity. Artificial Intelligence can reduce the accounting information risk by removing the weakness of internal control systems through the following solution. Artificial Intelligence can sense the weakness, comprehend the main problem, and do actions for removing the weakness through a programed expert decision making automatically [2].

\section{Sense}

Sense is similar to a border-control kiosk that uses computer vision technology such as facial recognition to uncover characteristics of weakness of internal controls. When this integrated with other technologies such as multispectral image analysis (e.g. video analytics, extensive information database and matching algorithms) it removes main weakness such as those related to inventory control systems.

\section{Comprehend}

Artificial Intelligence system also use technologies such as natural language processing, inference engine and expert systems to overcome the weakness of internal control system. Each of the technologies can be used through different applications. Date gathered from the sense section should be used by the technologies to be analyzed for the next section which is Act section.

\section{Act}

An Artificial Intelligence system acts in two ways; independently and in process. If Artificial Intelligence can work independently in regard to removing the weakness of internal controls, the Artificial Intelligence help to act this job without any human interfere to find, analysis and to decide how resolve the weakness 
without any human assistance. If the weakness suppose to be removed in process, then this kind of act would be applied for those internal control systems with discrete functions.

Artificial Intelligence, by reducing control risk, will be able to reduce auditor detection risk and acceptable audit risk. Detection risk is determined by dividing acceptable audit risk divided by inherent risk times control risk. Control risk is the risk related to weakness of internal control systems. Thus, Artificial Intelligence by reducing the control risk, this automatically reduce audit risk, increase audit quality, and therefore, reduce information risk for the users of the accounting information.

Moudud-Ul-Huq (2014) evidenced from Welch et al. (1998) study to introduce genetic algorithms as a potentially useful application by auditor for modeling fraud decisions [23]. Lensberg et al. (2006) applied genetic programming to bankruptcy prediction. This may also be useful in going-concern decisions when auditor form opinion on client with unpredictable business future. Neural networks have been proposed as a good application for a range of audit tasks. Due to their ability to model nonlinear relationships and handle incomplete data, neural networks may be particularly helpful for risk assessment tasks.

Koh et al. (2004) suggested the use of neural networks and data mining for going-concern predictions. They discovered that neural networks and decision trees are powerful tools in analyzing the complex, nonlinear and interactive relationships involved in going-concern analysis [18]. Fuzzy systems may be particularly useful for some audit tasks because of their inherent allowance of qualitative factors. For materiality decisions, this may be much better than typical quantitative rules of thumb (Comunale et al., 2005).

\section{$5 \quad$ AI and Internal Control Systems}

Moudud-Ul-Hug (2014) listed ten subjects of accounting topics that can be integrated with Artificial Intelligence. Those subjects are credit authorizing and screening, mortgage risk analysis, financial and economic analysis, risk rating of exchange traded, detection of regularities in security price movement, prediction of default and bankruptcy, risk analysis of fixed income investment, detection of management fraud, machine learning techniques to automatically identify characteristics of fraud and artificial intelligence in marketing.

Using Bataller and Harris (2018), we provide a practical model of using Artificial Intelligence to be applied for producing quality accounting information through mitigating weakness of internal controls in almost every industry. The following matrix shows managers to think and consider what type of internal control weakness can be automatically removed or augmented by Artificial Intelligence solutions. Figure 2. AI model for internal control systems 


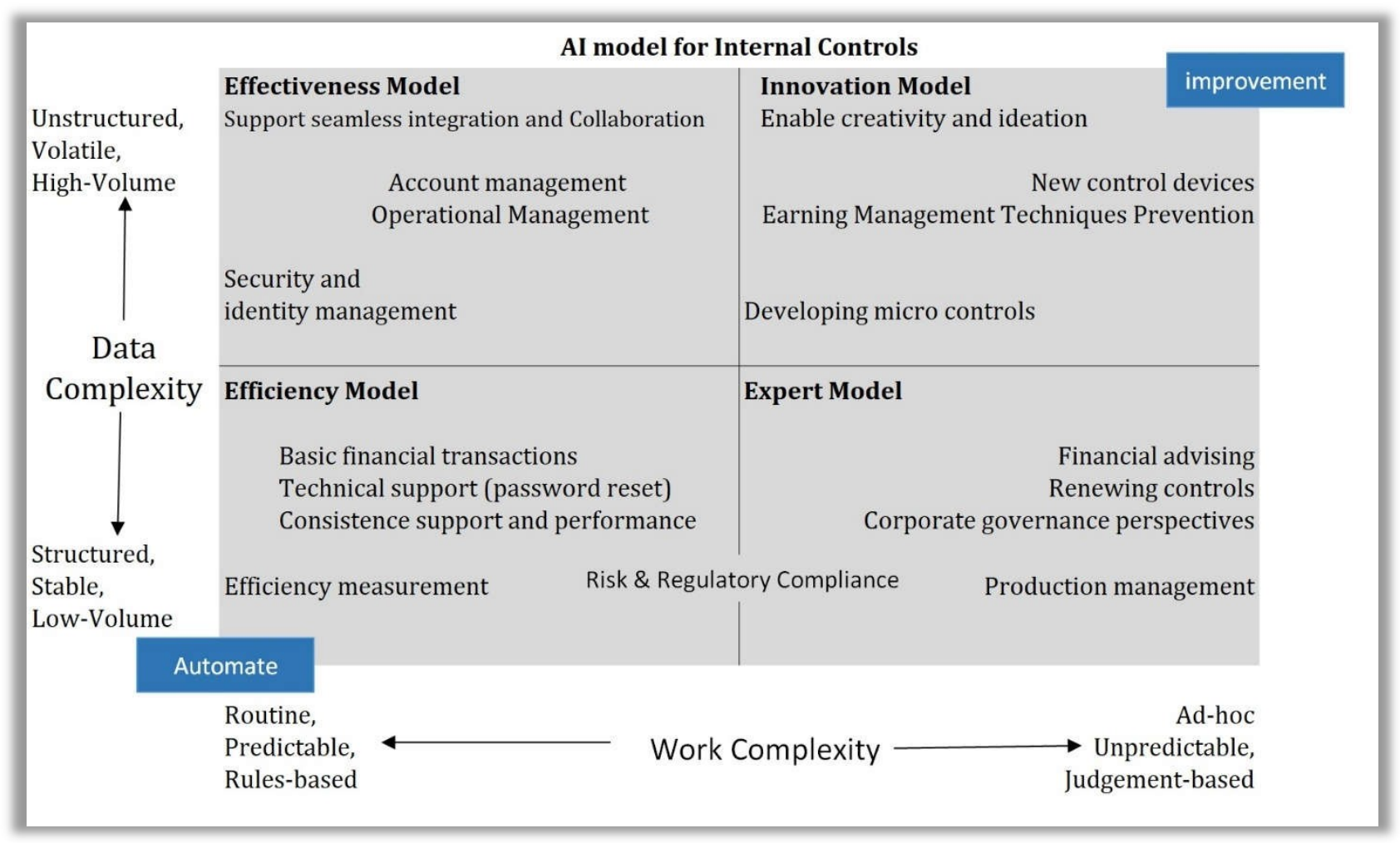

Source: Modified from Bataller and Harris (2018),

The matrix in figure 2 shows two dimensions of data and work complexity. Both of the two dimensions should be considered from automation and improvement of internal control function perspectives. Automation of routine tasks can improve overall productivity in producing accounting information and effectiveness of internal controls.

Efficiency model characterizes with more toutine activities based on those rules, procedures and criteria that make internal controls to be stronger. The main goal is to design those controls that satisfy costbenefit, quality performance and apply consistent in removing the weaknesses. In these Artificial Intelligence solution, humans involve with monitoring the accuracy and how the rules need to deal with the business conditions change. Machine learning capabilities should be applied for such rules. For example, with a minimal amounts of human intervention, internal controls monitor online data validity by applying codified knowledge and logic and make decision about accuracy and reliability of the data.

In expert model, Artificial Intelligence integrate judgmental tasks about how to remove the weakness of internal controls. Exactly like a financial advisor, the model provides the best solution based on the reality of the system condition and data, automated analysis and find the best solution robotically will be applied. Such system is able to search vast data sources, and making inferences and provide recommendations based on the knowledge. This model is similar to a medical diagnostic system which doctors find patient solution by testing different medical intricacy, the doctor judgement finally will be reported. Therefore, using natural language techniques and automated data analysis and searching, Artificial Intelligence will produce solution(s) for the weakness of the internal controls without need of human to intervene and judgement. 
Effectiveness model suggests improvement in overall ability of the internal control systems to produce reliable and relevant accounting information. This require to design the model based on a considerable amount of knowledge about the business entity characteristics, the regulatory and legislative environment, and industry specification. In this model, the system should assure that all transactions and accounts are updated on ongoing base and automatically uses can access to the information through virtual agents. Users of the information are increasingly using agents such as Google now on their smartphones. Technologies such as natural language processing or speech recognition allow searching the internet and finding the answers in form of a formatted report.

At the innovative model, Artificial Intelligence solution allows to generate new control methods, objectives, and methodology by recommendation based on current control environment. An example of how Artificial Intelligence can augment creative controls is an intelligent software that it can analysis a control activity and then provide recommendations to increase the likelihood that the control will be at risk. Also, the model should prevent those earning management techniques by analyzing transactions and account balances. While humans make decision and act, technology helps identify alternatives and optimize recommendation[2].

Risk and regulatory compliance should be considered in two models; efficiency and expert. One of the major risk in today business is the risk of violating on not compliant with law and regulation. Artificial Intelligence techniques such machine learning could be used to automatically detect and identify the risk.

Also, expert system could be used to find, analysis and generate solution using machine learning techniques.

\section{Conclusion}

To conclude, this research has contributed to knowledge in the following ways. First, the issue of using Artificial Intelligence in removing internal control systems weakness to produce quality accounting information initiative raised by this study. Second, to achieve this, a joint-working of accounting profession with Artificial Intelligence expertise to functionally developing software as well as applications for specific internal control systems are inevitable collaboration. Using Bataller and Harris (2018), we provide a practical model of using Artificial Intelligence to be applied for producing quality accounting information through mitigating weakness of internal controls in almost every industry. Efficiency model characterizes with more toutine activities based on those rules, procedures and criteria that make internal controls to be stronger. In expert model, Artificial Intelligence integrate judgmental tasks about how to remove the weakness of internal controls. Exactly like a financial advisor, the model provides the best solution based on the reality of the system condition and data, automated analysis and find the best solution robotically will be applied. Effectiveness model suggests improvement in overall ability of the internal control systems to produce reliable and relevant accounting information. At the innovative model, Artificial Intelligence solution allows to generate new control methods, objectives, and methodology by recommendation based on current control environment. 


\section{References}

[1]. AlAli, M., Almogren, A., Hassan, M.M., Rassan, Alam Bhuiyan, (2018), Improving risk assessment model of cyber security using fuzzy logic inference system, Computers \& Security, Vol. 74, pp. 323-339.

[2]. Bataller, C., \& Harris, J. (2018). Turning Artificial Intelligence into Business Value. Today: Accenture Emerging Technology Group.

[3]. Beynon, M.J., Peel, J.P., Tang, Y-C., (2004), The application of fuzzy decision tree analysis in an exposition of the antecedents of audit fees, Omega, Vol. 32, 3, p.p. 231-244.

[4]. Bizarro, P. A., \& Dorian, M. (2017). Artificial Intelligence: The Future of Auditing. Internal Auditing, 32(5), 21-26.

[5]. Brown, C E, Coakley, J, and Phllip, M E, (1995) Neural networks enter the World of Management Accounting. Management Accounting. May.51-57.

[6]. Canada, J., Sutton, S. G., \& Kuhn, J. R. (2009). The pervasive nature of IT controls. International Journal of Accounting and Information Management, 17(1), 106-119.

[7]. Canelas, J. Á. F., Martín, Q. M., \& Rodriguez, J. M. C. (2013). ARGUMENTATIVE SOX COMPLIANT AND QUALITY DECISION SUPPORT INTELLIGENT EXPERT SYSTEM OVER THE PURCHASE ORDERS APPROVAL PROCESS. Applied Mathematical and Computational Sciences, 4(4), 215-268.

[8]. Chang, S. Tsai CF, Shih, D-H Hwang, C.L (2008) The development of audit detection risk assessment system: Using the fuzzy theory and audit risk model, Expert Systems with Applications, Vol. 35, 3, pp. 1053-1067,

[9]. Cheh, J. J., Lee, J., \& Kim, I. (2010). Determinants of internal control weaknesses. Contemporary Management Research, 6(2), 159-176.

[10]. Dereli, T., Baykasoğlu, A., Sena Daş, G. (2007) Fuzzy quality-team formation for value added auditing: A case study, Journal of Engineering and Technology Management, Volume 24, Issue 4, pp. 366-394,

[11]. Doyle, J., W. Ge, and S. McVay. (2005). Determinants of weaknesses in internal control over financial reporting and the implications for earnings quality. Working paper, University of Utah, University of Michigan, and New York University

[12]. Elbannan, M. A. (2009). Quality of internal control over financial reporting, corporate governance and credit ratings. International Journal of Disclosure and Governance, 6(2), 127-149. 
[13]. Gramling, A., \& Schneider, A. (2018). Effects of reporting relationship and type of internal control deficiency on internal auditors' internal control evaluations. Managerial Auditing Journal, 33(3), 318-335.

[14]. Gupta, P. P., \& Nayar, N. (2007). Information content of control deficiency disclosures under the sarbanes-oxley act: An empirical investigation. International Journal of Disclosure and Governance, 4(1), 3-23.

[15]. ICAEW, (2017) “Artificial Intelligence and the Future of Accountancy”, ICAEW IT Faculty, Chartered Accountant’s Hall. Moorgate Place. London. UK

[16]. Kahraman, C., Kaya, I., \& Çevikcan, E. (2011). Intelligence decision systems in enterprise information management. Journal of Enterprise Information Management, 24(4), 360-379.

[17]. Kinkela, K., \& Harris, P. (2013). COSO UPDATES PRACTICE FRAMEWORK. Internal Auditing, 28(4), 35-40.

[18]. Koh, H. C., and Low, C. K. (2004). "Going concern prediction using data mining techniques”. Managerial Auditing Journal, 19(3), 462- 476.

[19]. Länsiluoto, A., Jokipii, A., \& Eklund, T. (2016). Internal control effectiveness - a clustering approach. Managerial Auditing Journal, 31(1), 5-34.

[20]. Ling, L. (2015). Research on enterprise internal control financial assessment system based on artificial intelligence. Revista Ibérica De Sistemas e Tecnologias De Informação, (16), 224-234.

[21]. Lu, H., Li, Y., Chen, M., Kim, H., \& Serikawa, S. (2018). Brain intelligence: Go beyond artificial intelligence. Mobile Networks and Applications, 23(2), 368-375

[22]. Maines, L. A., \& Wahlen, J. M. (2006). The nature of accounting information reliability: Inferences from archival and experimental research. Accounting Horizons, 20(4), 399425.

[23]. Moudud-Ul-Huq, S. (2014). The role of artificial intelligence in the development of accounting systems: A review. IUP Journal of Accounting Research \& Audit Practices, 13(2), 7-19.

[24]. Novac, C. (2000). Artificial intelligence system for decision -making process. "Ovidius" University Annals Constantza.Series Civil Engineering, 1(2), 261-266.

[25]. Segars, S. (2017). AI Today, Ai Tomorrow. In N. R. P. Ltd (Ed.), Global Artificial Intelligence Survey. UK: ARM NORTHSTAR 
[26]. Todoroi, D. (2013). How to create adaptable ROBO-intelligences? Academy of Economic Studies.Economy Informatics, 13(1), 27-39.

[27]. US Securities and Exchange Commission. (2004) Management's Reports on Internal Control Over Financial Reporting and Certification of Disclosure in Exchange Act Periodic Reports - Frequently Asked Questions. Washington DC. 6 October.

[28]. Wang, Q. (2007), “Artificial neural network as cost engineering methods in a collaborative manufacturing environment", International Journal of production economics, 109, pp. 5364. 